\title{
Effect of Hydrogen on the Electronic Properties of $\mathbf{G a A s}_{1-y} \mathbf{N}_{y}$ Heterostructures
}

\author{
M. Bissiri, V. Gaspari, G. Baldassarri H. v. H., \\ F. Ranalli, A. Polimeni, M. Capizzi, A. Nucara
}

INFM-Dip. di Fisica, Univ. di Roma "La Sapienza", 00185 Roma, Italy

\section{GEDDO}

INFM-Dip. di Fisica, Univ. di Parma, 43010 Fontanini (Parma), Italy

M. Fischer, M. Reinhardt And A. ForChel

Universität Würzburg, Technische Physik, 97074 Würzburg, Germany

We have performed photoluminescence measurements in order to study the optical properties of hydrogenated $\mathrm{GaAs}_{1-y} \mathrm{~N}_{y} / \mathrm{GaAs}$ heterostructures for $y$ ranging from 0 to 0.03 . Hydrogen irradiation leads to: (i) a progressive passivation of N-related recombination lines for low $\mathrm{N}$ content $(y \approx 0.001)$; (ii) a sizable blue shift of the band gap in the "alloy" limit $(y \approx 0.01)$. Thermal annealing restores the optical properties samples had before hydrogenation. These results can be accounted for by the formation of $\mathrm{N}^{-}-\mathrm{H}^{+}$ complexes and demonstrate that hydrogen irradiation provides a powerful tool for the analysis of photoluminescence spectra of $\mathrm{GaAs}_{1-y} \mathrm{~N}_{y}$.

PACS numbers: 78.66.Fd, 71.55.Eq, 78.55.Cr

Nitrogen is an isoelectronic impurity in GaP and in GaAs, where it substitutes group $\mathrm{V}$ atoms. $\mathrm{N}$ incorporation has been widely investigated in GaP, where it gives rise to the formation of several bound states deep in the band gap [1]. Photoluminescence (PL) spectra are characterized by sharp, strong resonances, each corresponding to radiative recombination from excitons bound either to isolated $\mathrm{N}$ atoms or to neighbor $\mathrm{NN}$ pairs [1-3]. The electronic properties of $\mathrm{GaAs}_{1-y} \mathrm{~N}_{y}$, instead, are less well understood, mainly because the isolated $\mathrm{N}$ level is here resonant with the GaAs conduction band [4]. The existence of this state, as well as of those related to NN pairs, has been proved by PL experiments under hydrostatic pressure $[5,6]$. At low $\mathrm{N}$ concentration $(y \approx 0.001)$, N-related transitions appear 
just below the band gap [7,8], while at higher concentrations, namely in the "alloy" limit $(y \geq 0.01)$, a strong red shift of the band gap [9] and a huge optical bowing are reported [10]. In this way emission energies of $1.3 \mu \mathrm{m}$ can easily be achieved, which makes $\mathrm{GaAs}_{1-y} \mathrm{~N}_{y}$ very promising for technological applications. Despite all theoretical and experimental investigations, the physical origin of the strong band gap reduction observed in the alloy limit is still argument of debate, as well as the exact assignment of the narrow, strong PL lines observed at low $\mathrm{N}$ concentration [8].

Recently, we have shown that hydrogen irradiation of ( InGa)(AsN)/(GaAs) quantum wells (QWs) with $y \geq 0.01$ causes a blue shift of the band gap PL, whose line width broadens and whose energy saturates at that of a nitrogen-free sample with the same In concentration [11]. We have also shown that thermal annealing restores the optical properties which the material exhibited before hydrogenation [12]. In the present work, we study the effect of $\mathrm{H}$ irradiation in $\mathrm{GaAs}_{1-y} \mathrm{~N}_{y} / \mathrm{GaAs}$ epilayers and QWs with very different $\mathrm{N}$ content. We show that $\mathrm{H}$ fully passivates $\mathrm{N}$-related lines in the diluted $\mathrm{N}$ limit, thus providing direct evidence of $\mathrm{N}-\mathrm{H}$ interaction. Moreover, we confirm that this interaction can account for the $\mathrm{H}$-induced band gap blue shift observed in the "alloy" limit.

A number of $\mathrm{GaAs}_{1-y} \mathrm{~N}_{y} / \mathrm{GaAs}$ heterostructures grown by solid source molecular beam epitaxy (MBE) have been investigated. $\mathrm{N}_{2}$ cracking was obtained by using a radio frequency plasma source. The $\mathrm{N}$ concentration has been determined by a combined analysis of X-ray diffraction and optical data. Nitrogen concentration of $\mathrm{GaAs}_{1-y} \mathrm{~N}_{y}$ epilayers $(0.1-0.6 \mu \mathrm{m}$ thick) ranges from $y \rightarrow 0$ to a very diluted $\mathrm{N}$ concentration ( $y \approx 0.001$ ), and to $y=0.01-0.03$. A set of $9 \mathrm{~nm}$ thick $\mathrm{GaAs}_{1-y} \mathrm{~N}_{y} / \mathrm{GaAs} \mathrm{QWs}$ have been also grown with nitrogen concentration varying from 0.013 to 0.028 . Post-growth treatment with atomic hydrogen was obtained by ion-beam irradiation from a Kaufman source with the samples held at $300^{\circ} \mathrm{C}$. The ion energy was about $100 \mathrm{eV}$ and the current density was few tens of $\mu \mathrm{A} / \mathrm{cm}^{2}$. A wide range of hydrogen doses $\left(10^{14}-10^{19}\right.$ ions $\left./ \mathrm{cm}^{2}\right)$ has been used in this study. $\mathrm{PL}$ was excited by the $515 \mathrm{~nm}$ line of an $\mathrm{Ar}^{+}$laser. The PL signal was dispersed by a single $1 \mathrm{~m}$ monochromator and detected by a Ge detector cooled at liquid nitrogen temperature.

PL spectra at temperature $T=10 \mathrm{~K}$ of two $\mathrm{GaAs}_{1-y} \mathrm{~N}_{y}$ epilayers with low nitrogen content are shown in Fig. 1. For $y \rightarrow 0$, the free exciton (FE) and carbon bound $(\mathrm{C}, \mathrm{X})$ exciton are clearly observed, as well as the free-to-bound transition $(\mathrm{e}, \mathrm{C})$ with its phonon replicas. For $y \approx 0.001$, a large number of sharp lines on the top of a broad background grows up in the energy range between 1.36 and $1.48 \mathrm{eV}$. The dependence of the PL bands on power density $(P)$ (not shown here) shows that the intensity of these N-related lines scales nearly linear with that of the $(\mathrm{e}, \mathrm{C})$ transition. For increasing $T$, a rapid quenching of the PL intensity is observed between 10 and $70 \mathrm{~K}$, which suggests a thermal activation energy for carrier bound to these states of the order of some tens of meV. 


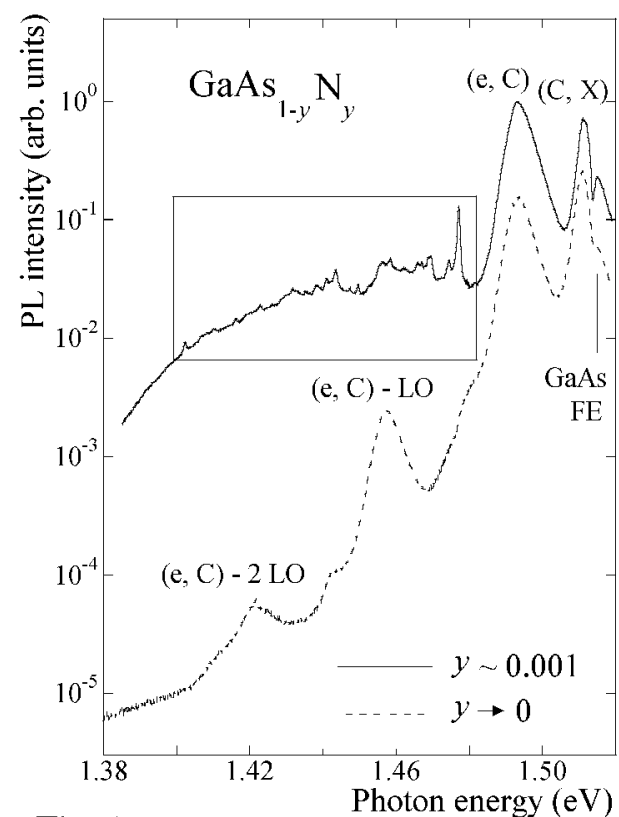

Fig. 1

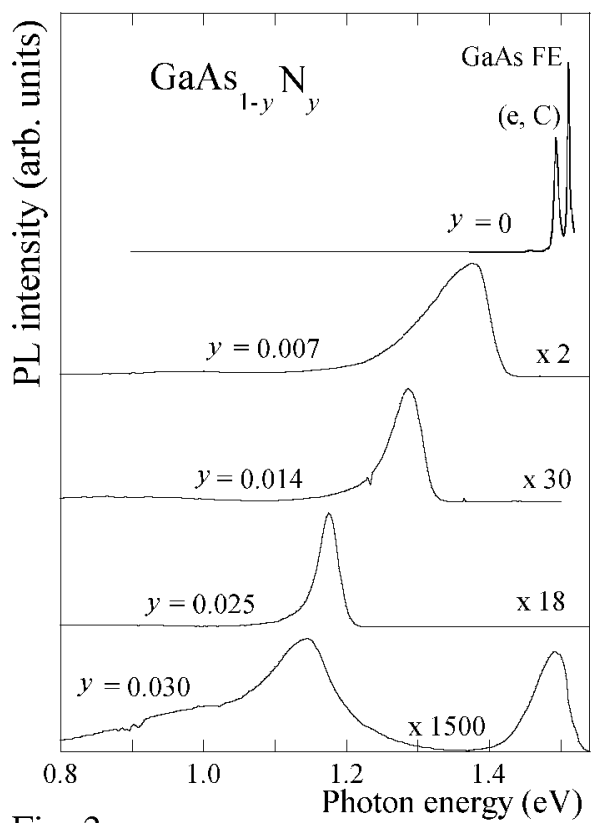

Fig. 2

Fig. 1. PL spectrum of a $\mathrm{GaAs}_{1-y} \mathrm{~N}_{y}$ epilayer (solid line) in the dilute limit of $\mathrm{N}$ concentration $(y \approx 0.001)$. PL of a GaAs epilayer (dashed line) is also shown for comparison.

Fig. 2. Normalized PL spectra at $T=10 \mathrm{~K}$ of different $\mathrm{GaAs}_{1-y} \mathrm{~N}_{y}$ epilayers in the alloy limit $(y=0-0.03)$. Normalization factors are given for each spectrum. Laser power density $P=50 \mathrm{~W} / \mathrm{cm}^{2}$.

PL spectra of four different $\mathrm{GaAs}_{1-y} \mathrm{~N}_{y}$ epilayers with $y$ varying from 0.007 to 0.03 are shown in Fig. 2, where no sharp features are seen. For increasing $\mathrm{N}$ content, the PL band corresponding to the material band gap shifts to lower energies. Its line shape at low $T$ and low $P$ is highly asymmetric, with a low energy tail due to localized states [13]. This behavior has been attributed to a repulsive interaction of the GaAs band gap with an N-related level resonant with the conduction band [14]. It has also been attributed to a strong mixing of levels with different $k$ values produced by the translational symmetry breaking of the lattice induced by $\mathrm{N}$ introduction [15].

The effect of hydrogen irradiation and thermal annealing is shown in Fig. 3 for the $y \approx 0.001$ sample. In Fig. $3 \mathrm{a}$, hydrogenation at various $\mathrm{H}$ doses, $d_{\mathrm{H}}$, leads to a progressive and complete passivation of N-related lines, as well as of the background. We stress that a very weak reduction of the intensity of $\mathrm{N}$ lines has been reported before only in the case of $\mathrm{N}$-doped GaP [3]. The passivation rate as a function of $d_{\mathrm{H}}$ varies from line to line. In Fig. 3a, we have labelled four representative lines, $A, B, C$, and $D$, which exhibit a different behavior 

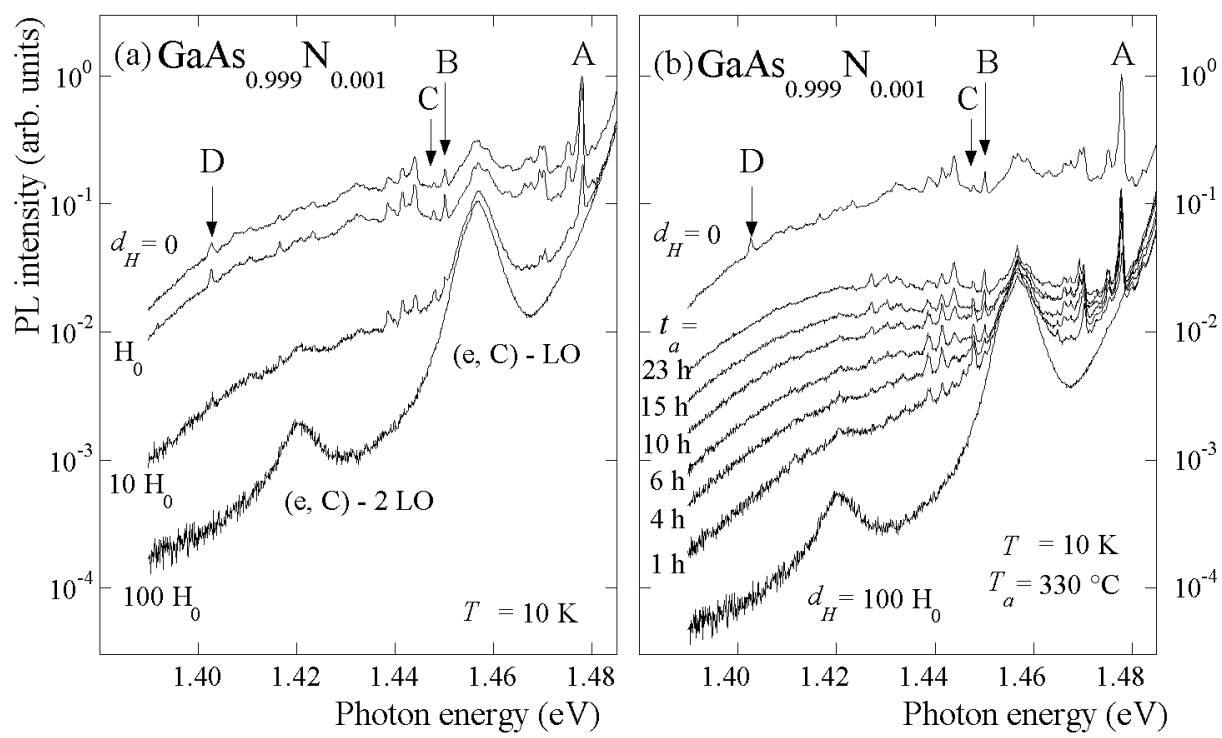

Fig. 3. (a) PL spectra at $T=10 \mathrm{~K}$ of $\mathrm{GaAs}_{0.999} \mathrm{~N}_{0.001}$ epilayer after hydrogen irradiation for different $\mathrm{H}$ doses $d_{\mathrm{H}}\left(H_{0}=10^{14}\right.$ ions $\left./ \mathrm{cm}^{2}\right)$. (b) PL spectra at $T=10 \mathrm{~K}$ of the hydrogenated sample $\left(d_{\mathrm{H}}=10^{16}\right.$ ions $\left./ \mathrm{cm}^{2}\right)$ for different thermal annealing time $t_{\mathrm{a}}$ (annealing temperature $T_{\mathrm{a}}=330^{\circ} \mathrm{C}$ ). In both parts of the figure four representative lines are labelled with letters, laser power density $P=10 \mathrm{~W} / \mathrm{cm}^{2}$.

under $\mathrm{H}$ irradiation. As an example, line $B$ quenches at higher rate than line $C$ does. Thermal annealing of the hydrogenated sample have been performed at fixed annealing temperatures $\left(T_{\mathrm{a}}=300,330\right.$, or $\left.400^{\circ} \mathrm{C}\right)$ as a function of the annealing time $t_{\mathrm{a}}$. Figure $3 \mathrm{~b}$ shows the PL spectra as a function of $t_{\mathrm{a}}$ for the same sample shown in Fig. 3a hydrogenated at $d_{\mathrm{H}}=10^{16}$ ions $/ \mathrm{cm}^{2}$ and annealed at $T_{\mathrm{a}}=330^{\circ} \mathrm{C}$. Most of the $\mathrm{N}$ lines progressively appear back in the spectrum for increasing $t_{\mathrm{a}}$, with a rate varying from line to line; see, e.g., lines $B$ and $C$. These effects can be accounted for by the formation of one (or more) $\mathrm{H}-\mathrm{N}$ bond, which is due to the large electronegativity difference between $\mathrm{N}$ and its atomic neighbors. Moreover, the behavior of $\mathrm{N}$ lines with $\mathrm{H}$ dose and annealing time suggests that $\mathrm{N}-\mathrm{H}$ bonds with different strengths are formed. In order to estimate the dissociation energy of the $\mathrm{N}-\mathrm{H}$ bonds, we need to determine the fraction, $N / N_{\mathrm{H} 0}$, of $\mathrm{N}-\mathrm{H}$ bonds left after each annealing. In the model introduced in Ref. [16],

$$
N / N_{\mathrm{H} 0}=\exp \left[-\nu t_{\mathrm{a}} \exp \left(-E_{\mathrm{a}} / k_{\mathrm{B}} T_{\mathrm{a}}\right)\right]
$$

where $\nu_{\mathrm{a}}$ is the attempt frequency [17], $E_{\mathrm{a}}$ is the dissociation energy of the $\mathrm{N}-\mathrm{H}$ bond and $k_{\mathrm{B}}$ is the Boltzmann constant. In our case, $N / N_{\mathrm{H} 0}$ is estimated by the ratio between the PL intensity $I\left(t_{\mathrm{a}}\right)$ of each line to its saturation value $I_{\text {sat }}$ 


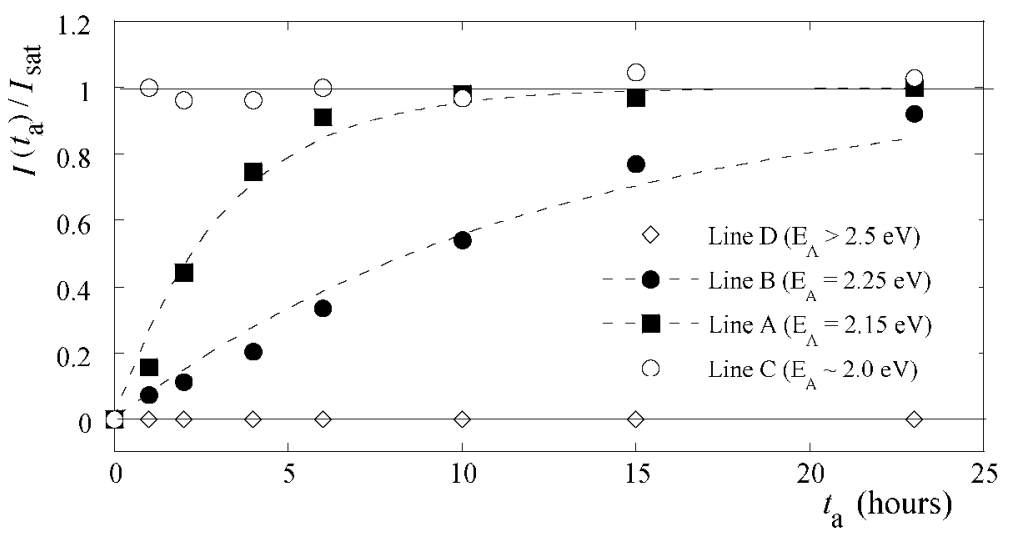

Fig. 4. Ratio between the PL intensity $I\left(t_{\mathrm{a}}\right)$ of four representative lines to its saturation value $I_{\text {sat }}$ as a function of the annealing time $t_{\mathrm{a}}$ (annealing temperature $T_{\mathrm{a}}=330^{\circ} \mathrm{C}$ ). Estimates of dissociation energies $E_{A}$ have been obtained fitting data with formula (1); see the text. Fits for line $A$ and $B$ are shown in dashed lines.

shown in Fig. $4^{*}$. We find four distinct values of $E_{\mathrm{a}}$, one for each of the four lines considered. A correlation is found between $E_{\mathrm{a}}$ and the quenching rate with $\mathrm{H}$ irradiation shown in Fig. 3. Line $C$ is passivated more slowly by $\mathrm{H}$, while its intensity saturates already at $t_{\mathrm{a}} \approx 1 \mathrm{~h}\left(E_{\mathrm{a}}\right.$ has the lowest values among the four lines). On the contrary, line $D$ is more easily passivated and does not recover its intensity either by thermal annealing at $T_{\mathrm{a}}=400^{\circ} \mathrm{C}$ and/or by very long annealing times. This implies a strong $\mathrm{N}-\mathrm{H}$ bond, as confirmed by a dissociation energy greater than $2.8 \mathrm{eV}$. Finally, $E_{\mathrm{a}}$ values for line $A$ (the most intense one) and $B$ are 2.15 and $2.25 \mathrm{eV}$, respectively. $\mathrm{H}$ irradiation and thermal annealing permit, therefore, to classify N-related optical transitions on the ground of their $\mathrm{N}-\mathrm{H}$ bond strength, which may depend on the type and the symmetry of $\mathrm{N}$ complex (i.e., isolated $\mathrm{N}, \mathrm{NN}$ pair or $\mathrm{N}$ cluster).

The smooth background observed in the $y \approx 0.001$ sample has a PL line shape which resembles the Urbach tail in disordered semiconductors. Its behavior with $\mathrm{H}$ irradiation and thermal annealing suggests that it is also related to $\mathrm{N}$ incorporation.

We now briefly discuss the effect of $\mathrm{H}$ in the limit of high $\mathrm{N}$ content. Figure 5 shows PL spectra of $\mathrm{GaAs}_{1-y} \mathrm{~N}_{y}$ QWs with $y=0.2$. The band gap blue shifts with increasing $d_{\mathrm{H}}$, approaching the value it has in GaAs, and no sizable broadening of the PL line shape is observed. Thermal annealing at $T_{\mathrm{a}}=300^{\circ} \mathrm{C}$ breaks $\mathrm{N}-\mathrm{H}$ bonds and, for increasing $t_{\mathrm{a}}$, the band gap recovers the value it had before hydrogenation. Therefore, this behavior is similar to that observed in the

${ }^{*}$ The intensity of each line was calculated subtracting the contribution due to the broad background. 


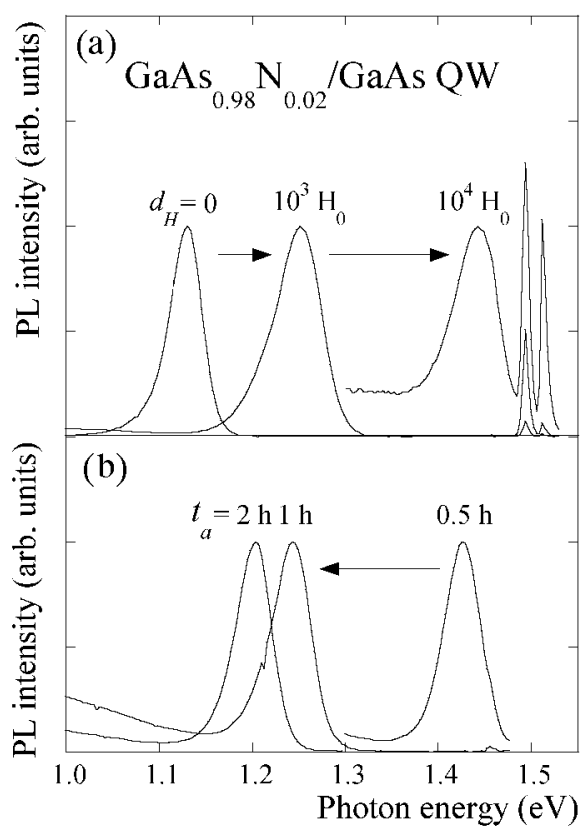

Fig. 5. Normalized PL spectra at $T=10 \mathrm{~K}$ of a $\mathrm{GaAs}_{0.98} \mathrm{~N}_{0.02} / \mathrm{GaAs} \mathrm{QW}$ for (a) different $d_{\mathrm{H}}$ and for (b) subsequent different annealing times $t_{\mathrm{a}}\left(T_{\mathrm{a}}=300^{\circ} \mathrm{C}\right)$. Normalization factors are given for each spectrum. Laser power density $P=50 \mathrm{~W} / \mathrm{cm}^{2}$.

dilute limit, thus suggesting that $\mathrm{N}$ associated wave function maintains a strongly localized "impurity-like" character even in the alloy limit.

In conclusion, all results presented here can be accounted for by the formation of an $\mathrm{N}-\mathrm{H}$ bond, with a point group symmetry for the resulting complex different from that of the original $\mathrm{N}$ state. This lowers the effective number of electrical active $\mathrm{N}$ centers in the material and causes a full passivation of recombination lines of exciton bound to N-related complexes in the dilute limit. Similarly, in the alloy limit, $\mathrm{H}$ produces a reduction of the band gap red shift related to $\mathrm{N}$ incorporation.

\section{References}

[1] D.G. Thomas, J.J. Hopfield, Phys. Rev. 150, 680 (1966).

[2] B. Gil, J. Camassel, P. Merle, H. Mathieu, Phys. Rev. B 25, 3987 (1982).

[3] M. Singh, J. Weber, Appl. Phys. Lett. 54, 424 (1988).

[4] D.J. Wolford, J.A. Bradley, K. Fry, J. Thompson, in: Proc. 17th Int. Conf. on Physics of Semiconductors, Eds. J.D. Chadi, W.A. Harrison, Springer, New York 1984 , p. 424. 
[5] X. Liu, M.-E. Pistol, L. Samuelson, S. Schwetlick, W. Seifert, Appl. Phys. Lett. 56, $1451(1990)$.

[6] X. Liu, M.-E. Pistol, L. Samuelson, Phys. Rev. B 42, 7504 (1999).

[7] T. Makimoto, H. Saito, T. Nishida, N. Kobayashi, Appl. Phys. Lett. 70, 2984 (1997).

[8] J.D. Perkins, A. Mascarenhas, Y. Zhang, J.F. Geisz, D.J. Friedman, J.M. Olson, S.R. Kurtz, Phys. Rev. Lett. 82, 3312 (1999).

[9] S. Francoeur, S.A. Nikishin, C. Jin, Y. Qiu, H. Temkin, Appl. Phys. Lett. 75, 1538 (1999).

[10] S.-H. Wei, A. Zunger, Phys. Rev. Lett. 76, 664 (1996).

[11] A. Polimeni, G. Baldassarri H. v. H, M. Bissiri, M. Capizzi, M. Fischer, M. Reinhardt, A. Forchel, Phys. Rev. B 63, 195320 (2001).

[12] G. Baldassarri H. v. H, M. Bissiri, A. Polimeni, M. Capizzi, M. Fischer, M. Reinhardt, A. Forchel, Appl. Phys. Lett. 78, 3472 (2001).

[13] I.A. Buyanova, W.M. Chen, G. Pozina, J.P. Bergman, B. Monemar, H.P. Xin, C.W. Tu, Appl. Phys. Lett. 75, 501 (1999).

[14] W. Shan, W. Walukiewicz, J.W. Ager III, E.E. Haller, J.F. Geisz, D.J. Friedman, J.M. Olson, S.R. Kurtz, Phys. Rev. Lett. 82, 1221 (1999).

[15] P.R.C. Kent, A. Zunger, Phys. Rev. Lett. 86, 2613 (2001).

[16] Hydrogen in Semiconductors, Eds. J.I. Pankove, N.M. Johnson, Semiconductors and Semimetals, Vol. 34, Academic Press, New York 1991.

[17] For attempt frequency we have assumed the value for $\mathrm{N}-\mathrm{H}$ modes measured in S. Kurtz, J. Webb, L. Gedvillas, D. Friedman, J. Geisz, J. Olson, R. King, D. Joslin, K. Karam, Appl. Phys. Lett. 78, 748 (2001). 